\title{
The use of Taguchi method in the design of plastic injection mould for reducing warpage
}

\begin{abstract}
Plastic injection moulding is one of the most important polymer processing operations in the plastic industry today. However, lack of skill in mould making and injection moulding machine control will lead to defective plastic product. Warpage is one type of defect that usually appears in products with thickness less than $1 \mathrm{~mm}$.

This project is going to fabricate a mould that produced a thin plate with dimension $120 \mathrm{~mm}$ $\times 50 \mathrm{~mm} \times 1 \mathrm{~mm}$. The thin plate will be used for warpage testing. In mould fabrication, the mould base that purchase will be machined and assembled. After that, the mould is fixed on the injection moulding machine. The machine setting should be made to produce the product. Then, the product will be used for testing on the effective factors in warpage problem by applying the experimental design of Taguchi method.

From the results, it shows that the most effective factor on the warpage is melt temperature. The filling time only slightly influenced on the warpage. The optimum parameters that can minimize the warpage defect are melt temperature $\left(240{ }^{\circ} \mathrm{C}\right)$, filling time $(0.5 \mathrm{~s})$, packing pressure $(90 \%)$ and packing time $(0.6 \mathrm{~s})$.
\end{abstract}

Keyword: Plastic injection mould; Taguchi methods; Experimental design; Warpage 